\title{
Analysis of Agricultural Non-point Source Pollution in Henan Province (China) from the Perspective of Time and Space
}

\section{Aping Chang $\dagger$, Hua Qiong and Zheng Binguo}

School of Economics, Zhengzhou University of Aeronautics, Zhengzhou 450046, PR China

†Corresponding author: Aping Chang; guobinzheng@126.com

Nat. Env. \& Poll. Tech.

Website: www.neptjournal.com

Received: 08-03-2021

Revised: 21-04-2021

Accepted: 03-05-2021

Key Words:

Agricultural Non-point source

Pollution

Analysis

Chemical fertilizer

\section{ABSTRACT}

Henan is China's most populous agricultural province. Wheat, cotton, oil crops, and other farming and animal husbandry industries rank first in China in terms of output value. The agricultural sector has grown significantly, and rural populations' living standards have greatly improved. The effects of rural urbanization can be seen all over the place. However, the rural economy's rapid growth has resulted in a slew of environmental contamination issues. Chemical fertilizer emissions of chemical oxygen demand (COD) and total nitrogen (TN) have been decreasing for a long time in Henan Province, whereas total phosphorus (TP) emissions are increasing. The usage load of pesticides went high in Zhoukou, Nanyang, Shangqiu, Xinyang, Xinxiang, and Zhumadian. The application of agricultural film was relatively common in Nanyang, Zhoukou, Anyang, Xinyang, Zhumadian, Kaifeng, and Shangqiu. Wheat, corn, and oil-bearing crop stalks are the main sources of crop solid waste in Henan Province, and the solid waste generated by these three crops accounted for $93.96 \%$ of the province's total amount. In Zhumadian, Zhoukou, Nanyang, and Shangqiu, there was a lot of crop stalk trash.

\section{INTRODUCTION}

Henan Province is a major agricultural province and a major food province in China (Zhang \& Shou 2021). The output value of wheat, cotton, oil crops, and other cultivation and animal husbandry industries are among the best in the country. In recent years, the rural economy of Henan has developed rapidly. Some regions have achieved their goal of prosperity. Rural dwellers' living standards have substantially improved, and rural urbanization can be seen everywhere (Yuan et al. 2018, Yan et al. 2021). However, the rural economy's rapid growth has resulted in a slew of environmental contamination issues (Zhang et al. 2020, Zhou et al. 2020), which are mainly manifested in the pollution caused by the large-scale use of pesticides and fertilizers (Zheng et al. 2020, Liu et al. 2017, Gu et al. 2015) and the improper use of crop straws and other solid wastes in agricultural production ( $\mathrm{Li}$ et al. 2016, Qiu et al. 2016, Zhang et al. 2016).

The key concerns of agricultural non-point source pollution in rural areas of Henan Province are analyzed and studied based on the third agricultural census data and the statistical yearbook of Henan Province over the years. The findings of the study have significant practical implications for the long-term development of rural areas in emerging countries.

\section{MATERIALS AND METHODS}

To estimate the agricultural non-point source pollution loads in Henan Province, the agricultural input and output database was established; the database includes the prefecture-level city of Henan Province annual data of the pure consumption of nitrogen, phosphate, and compound fertilizers; the application of pesticide; and the consumption of agricultural film from 2010 to 2019. In addition, the agriculture acreage for the prefecture-level city of Henan Province was included.

\section{RESULTS AND DISCUSSION}

Consumption of chemical fertilizers: Fertilization in fields releases large amounts of nitrogen and phosphorus compounds into soil and water, causing soil and water pollution (Xue et al. 2020). According to the national pollution census in 2010, the total nitrogen (TN) and total phosphorus (TP) loads from agricultural non-point sources (AGNPS) accounted respectively for $57.2 \%$ and $67.4 \%$ of the total emissions in China (Xue et al. 2020). Agricultural chemical fertilizers mainly include nitrogen fertilizer, phosphate fertilizer, potash fertilizer, and compound fertilizer in China. From 2009 to 2019 , the trends of scalar fertilization and fertilization in Henan Province are shown in Fig.1.

From 2009 to 2015, the scalar amount of chemical fertilizer application in Henan increased year by year. It was $6,282,700$ tons in 2009 , but increased to $7,160,900$ tons in 2015. From 2016 to 2019, the scalar amount decreased year by year and reduced to $6,667,200$ tons in 2019 . The amount of fertilizer application was also determined in this work 
since the scalar amount of chemical fertilizer application is related to the area of cultivated land, which changed in Henan over the study period. The findings revealed that the fertilizer application pattern in Henan has been steady from 2009 to 2019. From Fig. 2, we can know the fertilizer application load increased year by year from 2009 to 2015 . It was $767.42 \mathrm{~kg} \mathrm{ha}^{-1}$ in 2009 and increased to $883.42 \mathrm{~kg} \cdot \mathrm{ha}^{-1}$ in 2015. It began to decline in 2019 and fell to $818.64 \mathrm{~kg} \cdot \mathrm{ha}^{-1}$ in 2019. Based on the two indicators, since 2016, the amount of fertilizer input to agricultural land in Henan Province has decreased year by year in terms of both total amount and unit intensity indicators.

As for the spatial distribution of agricultural fertilizer application in Henan, the average scalar amount of agricultural fertilizer application in 18 local cities in 2019 was 370,401 tons, and the cities with higher scalar amount levels were Zhoukou (860678 tons), Shangqiu (778648 tons), Nanyang (762346tons), Zhumadian (733984tons), Xinxiang (519743tons), Xinyang (448822tons), and Anyang (432097tons), These seven cities accounted for $68 \%$ of the

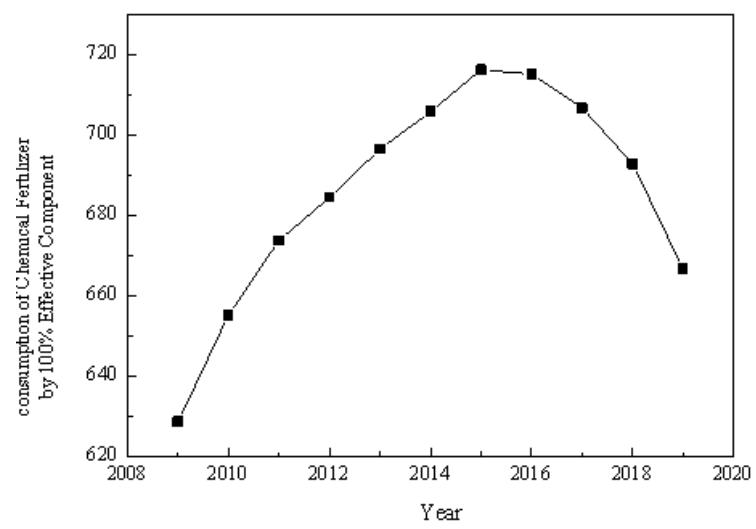

Fig. 1: Consumption of chemical fertilizer by $100 \%$ effective component.

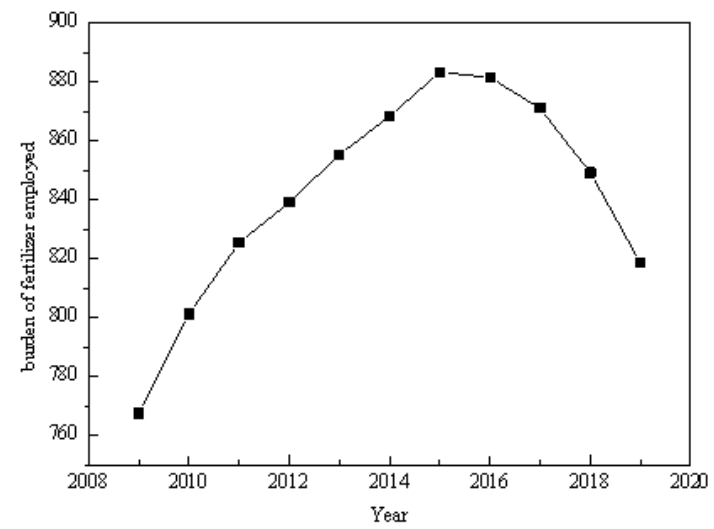

Fig. 2: Load of fertilizer employed. whole agricultural fertilizer scalar amount in Henan. To eliminate the impact of different cultivated land areas on the conversion of agricultural fertilizers, we calculated the fertilizer usage load of 18 local cities in 2019. The results showed that in 2019 the average level of fertilizer usage in 18 local cities was $819.54 \mathrm{~kg}^{-h^{-1}}$ and the cities with a higher amount than the average were Xinxiang (1096.69 kg.ha $\left.{ }^{-1}\right)$, Shangqiu (1093.58 kg.ha ${ }^{-1}$ ), Pingdingshan (1061.52 kg.ha ${ }^{-1}$ ), Anyang (1059.25 kg.ha' ${ }^{-1}$ ), Puyang (1037.08 kg.ha-1), Zhoukou (1003.00 kg.ha- $\left.{ }^{-1}\right)$, Jiaozuo (992.45 kg.ha $\left.{ }^{-1}\right)$ and Luohe $\left(908.85 \mathrm{~kg} \cdot \mathrm{ha}^{-1}\right)$. The city with the highest amount was Xinxiang which reached $1096.69 \mathrm{~kg} \cdot \mathrm{ha}^{-1}$ and the lowest one was Sanmenxia with $485.68 \mathrm{~kg} \cdot \mathrm{ha}^{-1}$. Chemical fertilizer application on agricultural land was extremely diverse depending on the spatial distribution in terms of total volume and intensity.

Chemical fertilizer pollution: The nitrogen fertilizer pollution load in Henan Province was calculated using the following equation, $\mathrm{L}(\mathrm{n})=\mathrm{M}(\mathrm{n}) \times \operatorname{ROC}(\mathrm{n})$, Where, $\mathrm{L}(\mathrm{n})$ is the nitrogen fertilizer pollution load $\left(\mathrm{kg} \cdot \mathrm{ha}^{-1}\right), \mathrm{M}(\mathrm{n})$ is net nitrogenous fertilizer consumption $\left(\mathrm{kg}^{\mathrm{h}} \mathrm{ha}^{-1}\right), \operatorname{ROC}(\mathrm{n})$ is run-off coefficient of nitrogen fertilizer pollution (Zhang et al. 2020). The phosphorus fertilizer pollution load in Henan Province was calculated using the following equation, $\mathrm{L}(\mathrm{p})$ $=\mathrm{M}(\mathrm{p}) \times \mathrm{ROC}(\mathrm{p}) \times 43.33$, Where, $\mathrm{L}(\mathrm{p})$ is the phosphorus fertilizer pollution load $\left(\mathrm{kg} \cdot \mathrm{ha}^{-1}\right), \mathrm{M}(\mathrm{p})$ is net phosphorus fertilizer consumption ( $\left.\mathrm{kg} \cdot \mathrm{ha}^{-1}\right), \mathrm{ROC}(\mathrm{p})$ is the loss coefficient of phosphorus fertilizer pollution (Zhang et al. 2020).

The pollution loads of nitrogen fertilizer and phosphate fertilizer were calculated in 18 local cities in Henan in 2019. The 8 cities with higher nitrogen fertilizer pollution load than the average were Zhoukou, Nanyang, Xinyang, Shangqiu, Xinxiang, Zhumadian, Anyang, and Kaifeng in the order from high to low, accounting for $74.55 \%$. Meanwhile, the 7 cities where the phosphate fertilizer pollution load exceeded the average were Zhoukou, Nanyang, Shangqiu, Zhumadian, Xinyang, Xinxiang and Kaifeng, accounting for $72.08 \%$.

The CODTN emissions generated by fertilizer application in Henan Province are decreasing, whereas the TP emissions are growing, according to the analysis. Fertilizer TN emissions account for around $37 \%$ of agricultural source TN emissions. Fertilizer TP emissions account for roughly $36 \%$ of agricultural source TP emissions. CODTN and TP emissions are high in Puyang, Anyang, Shangqiu, Xuchang, Kaifeng, and other northeast Henan plain areas, but emissions are low in the southern hilly mountain area, Xinyang, and Nanyang. This phenomenon may be caused by the following aspects: first, the cultivated land resources and population density of southern hilly and mountainous areas are smaller than a plain area; second, the surface water resources of southern hilly and mountainous area are rich, the threat to 
local water resources caused by farmland fertilizer source pollution is small. Nanyang, Shangqiu, Xinyang, Zhoukou, and Kaifeng account for almost $60 \%$ of the total quantity of agriculture pollution emissions in Henan Province.

Consumption of pesticides and their environmental effects: Pesticides play an important role in increasing productivity, reducing crop loss, controlling disease vectors, ensuring the provision of adequate healthy food, and reducing the labor, fuel, and machinery needed for crop protection activities. China consumes around $43 \%$ of global pesticides on less than $9 \%$ of global cropland. The average intensity of pesticide use per unit of cropland in China is $13.1 \mathrm{~kg}$ per hectare, versus $3.7 \mathrm{~kg}$ per hectare in Asia, and $2.6 \mathrm{~kg}$ per hectare worldwide (Zhu \& Wang 2021). While agricultural pesticides are an important tool in agriculture and other industries, their widespread use poses a significant environmental threat due to their toxic effects and bioaccumulation tendencies in non-target organisms (Sahin \& Karpuzcu 2020). Pesticides are frequently linked to risks to soil health, ecosystem function, and human safety (Yang et al. 2021). China is the largest agricultural country in the world (Kuang et al. 2020), and the average amount of pesticides used per hectare is about 1.5 to 4 times as much as the world average. Pesticides can go into surface water through surface runoff, soil erosion, spray drift, drainage, and leaching. Henan Province is one of the regions with the highest population density, developed agriculture, and the fastest growth in national economic output and per capita income in China. The main pesticides used in agricultural production in Henan Province are dichlorvos, trichlorfon, omethoate, parathion, parathion methyl, methamidophos, and other organophosphates and carbamate mushrooms such as carbaryl, as well as packs pyrethroids such as fenvalerate and cypermethrin. The utilization rate of pesticides sprayed on crops is about $20 \% \sim 30 \%$, and the other $70 \% \sim 80 \%$ are lost to non-target crops, soil, or waters. The residual pesticides in the soil environment of Henan Province mainly include atrazine, pentachlorophenol, malathion, DDT and glyphosate.

Figs. 3 and 4 show that the amount of pesticide applied in Henan Province increased from 121,400 to 130,100 tonnes from 2009 to 2013, then declined from 129,900 to 107,200 tonnes from 2014 to 2019. From the viewpoint of the intensity index of pesticide application per cultivated land unit, it increased yearly in 2009-2014, from $14.82 \mathrm{~kg} \cdot \mathrm{ha}^{-1}$ to $15.99 \mathrm{~kg} \cdot \mathrm{ha}^{-1}$, and decreased year by year from 2015 to 2019 , from $15.88 \mathrm{~kg} \cdot \mathrm{ha}^{-1}$ to $13.17 \mathrm{~kg} \cdot \mathrm{ha}^{-1}$. The results showed that pesticide application in Henan has begun to drop and stabilize in recent years, both in terms of total amount and intensity index, and agricultural production consumption has decreased.
From the spatial distribution of pesticide usage in Henan, the average usage in 18 provincial cities in 2019 was 5,957 tons. Cities with amounts higher than average were Zhoukou (18192), Nanyang (14620), Shangqiu (11476), Xinyang (10371), Xinxiang (8309), and Zhumadian (7613), accounting for $65.82 \%$. In 2019 , the average pesticide usage per unit cultivated area in 18 cities was 12.60 tons/1000 hectares. The above-average cities were Zhoukou (21.20), Jiaozuo (18.83), Xinxiang (17.53) and Shangqiu (16.12), Sanmenxia (14.13), Nanyang (13.87), and Anyang (13.81).

Consumption of agricultural mulch film and its environmental effects: Agricultural mulch film is widely used in agriculture for improving agricultural production ( $\mathrm{Li}$ et al. 2021, 2020), but it is also the main pollution source of agricultural non-point source pollution in Henan Province. Agricultural mulch film is a synthetic polymer compound material, which will stay in the soil for a long time if it is not cleaned or picked up in agricultural production. In recent decades, with the expansion of global mulch film consumption, the use of agricultural mulch film has also increased

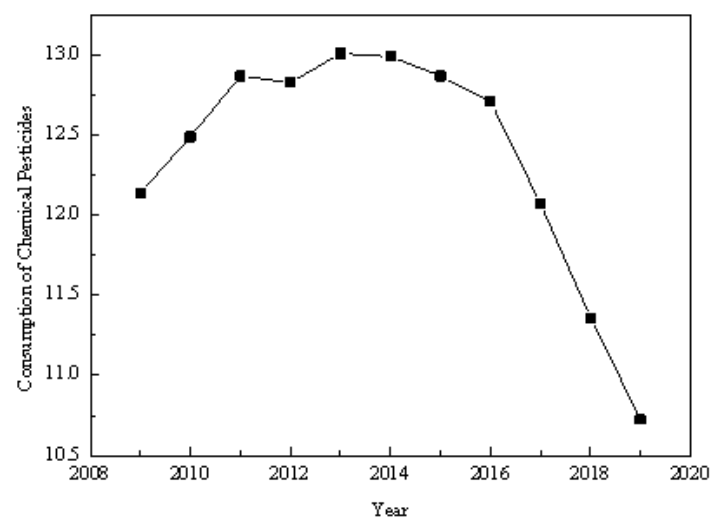

Fig. 3: Consumption of chemical pesticides.

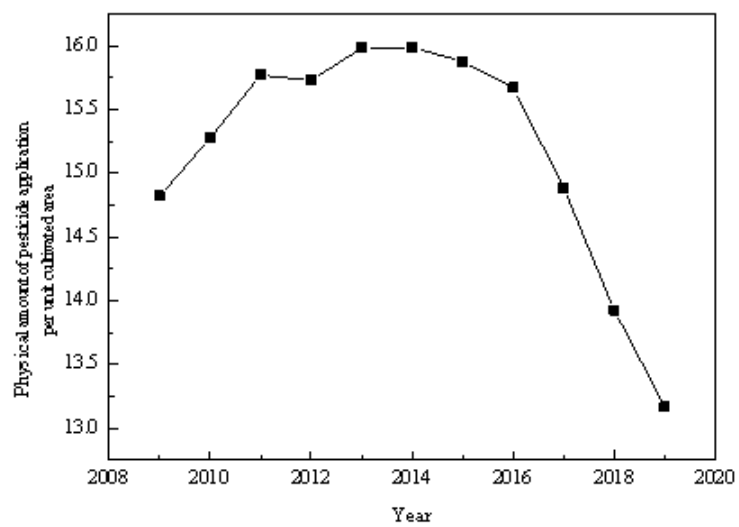

Fig. 4: Physical amount of pesticide application per unit cultivated area. 
yearly in China. Debris is likely to remain in the soil due to the thin mulch film's fragility. The mulch is primarily made of polyvinyl chloride, which is difficult to decompose and recycle (Liu et al. 2019). The remaining mulch film in the soil degrades the soil structure and alters the normal movement and distribution of water and nutrients (Liu et al. 2019). Currently, the agricultural mulch film generally used in Henan Province is an ultra-thin film with a thickness of less than $0.008 \mathrm{~mm}$, which has poor ductility, wear resistance, and a short period of use. After being fragmented, it will remain in the soil and extremely difficult to clean.

There is little variation in the average dosage of agricultural mulch film for different crops, and the average dosage of agricultural mulch film for tobacco and watermelon 45 $\mathrm{kg} \cdot \mathrm{hm}^{-2}$, the average dosage of agricultural mulch film for peanuts is $33.75 \mathrm{~kg} \cdot \mathrm{hm}^{-2}$, and the average dosage of agricultural mulch film for garlic is $37.5 \mathrm{~kg} \cdot \mathrm{hm}^{-2}$. The total residue of agricultural mulch film in the cultivated soil is $8.19 \sim 17.60$ $\mathrm{kg} \cdot \mathrm{hm}^{-2}$ in Henan Province, with an average of $0.10 \mathrm{~kg} \cdot \mathrm{hm}^{-2}$. The residual membrane bigger than $100 \mathrm{~cm}^{2}$ is overwhelming, accounting for $71.9 \%$ on average, $20 \sim 100 \mathrm{~m}^{2}$ accounting for $19.2 \% ; 2 \sim 20 \mathrm{~cm}^{2}$ being $7.3 \%$, and debris less than $2 \mathrm{~cm}^{2}$ being only $1.6 \%$. The residual mulch film in the soil has a large molecular mass and stable performance and, it can stay in the soil and cannot decompose under natural conditions for a long time. The residual mulch film poses a great threat to the soil environment, agricultural production, ecological environment, livestock, and human health, especially to soil and crop growth and development.

Fig. 5 shows the amount of agricultural mulch film used in Henan Province from 2009 to 2016. It can be seen that the usage continues to rise, with the minimum usage of 141,400 tons and maximum usage of 163,100 tons in 2013. From 2017 to 2019, agricultural mulch film usage was declining year by year. From 157,300 tons it fell to 150,800 tons and tended to be stabilized. As to the plastic film usage, during 2019 in the 18 local cities, Nanyang (16.78), Zhoukou (12.83), Anyang (12.05), Xinyang (9.26), Zhumadian (8.35), Kaifeng (8.32), and Shangqiu (8.02) accounted for respectively more than $8 \%$ of the total agricultural mulch film usage. These 7 cities accounted for $75.61 \%$ in total.

The Yield of agricultural straw and its environmental effects: Agricultural straw is an important byproduct of agricultural systems. With the continuous and active support of Chinese authority to modern agriculture, China's grain acreage and production are gradually increasing, and the amount of crops straw is also increasing yearly. Agricultural straws' functions can be broadly split into three categories: The first is that straw can be utilized as a source of nourishment and as a feed and fertilizer (Wang et al. 2021, Zhang et al. 2021).
The second is energy, which can be employed in an industrial project because of its biomass (Yang et al. 2021). Straw can be utilized as a raw material for technical reasons as the third function (Rojas et al. 2019). China offers some policies and financial supports for the comprehensive use of straw (Zou et al. 2020). However, due to various restrictions, $60 \%$ of straw resource processing is effectively used as fertilizers, feed, and raw materials, while $40 \%$ of the processing is still not used effectively or even discarded at will, which may cause environmental pollution.

Open burning is a prevalent phenomenon during harvest seasons in certain areas of Indoor burning for energy has been regarded to cause health difficulties, particularly lung cancer as well as cardiovascular and respiratory disorders, in Henan Province, generating significant air pollution (Sun et al. 2020). The main characteristic of grain cultivation in Henan Province is numerous in crop variety with large quantities, but at the same time, it faces the big problem of straw processing. The total amount of crop stalk resources in Henan Province can be estimated based on the amount of crop production, and the estimation method is as follows, $S=\sum_{j=1}^{k} s_{j} d_{j}$, where $S$ is the number of straw resources, $s_{j}$ is the yield of a certain crop, and $d_{j}$ is the grass and valley of a certain crop, as shown in Table 1 . The estimation of straw production in Henan Province in 2019 is shown in Table 2.

From the calculated proportion of straw stalk in the above table, the main sources of crop straw in Henan are wheat, corn, and oilseeds, which produce $93.96 \%$ of the total straw. We estimated the straw stalk output ratio from the production of major crops in each city in 2019. According to the findings, the cities with the highest ratios were Zhumadian (13.48\%), Zhoukou (13.17\%), Nanyang (12.22\%), and Shangqiu (10.87\%), accounting for 49.74 per cent of the total. The rate of exploitation of straw resources is low (less than $60 \%$ ), while the possibility of resource utilization is great.

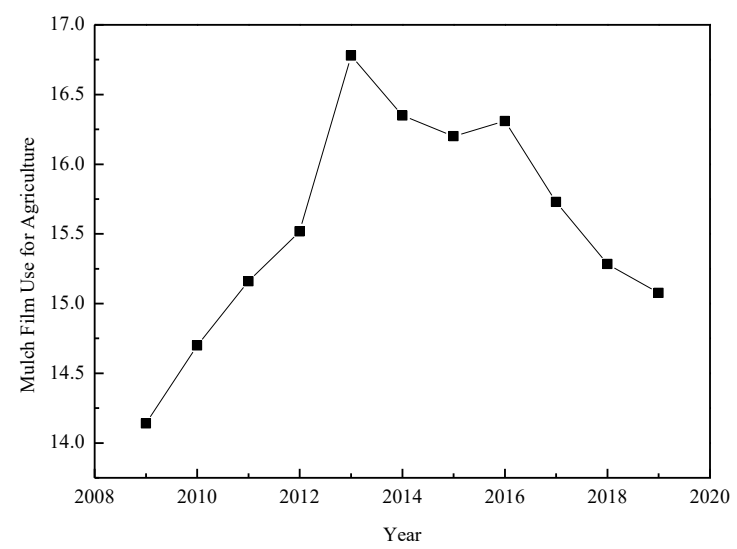

Fig. 5: The amount of agriculture mulch film. 
Table 1: Grain-straw ratio.

\begin{tabular}{|lllll|}
\hline \multicolumn{3}{|c|}{ grain-straw ratio } & \\
\hline paddy & 1.0 & wheat 1.4 & corn & 2.0 \\
beans & 1.5 & cotton & 3.0 & potato 0.5 \\
bast fiber crop 1.0 & oilcrops 2.0 & carbohydrate crop 0.1 \\
\hline
\end{tabular}

Table 2: Henan Province's straw production in $2019\left(\times 10^{7} \mathrm{~kg}\right)$.

\begin{tabular}{|llllllllll|}
\hline & Paddy & Wheat & Corn & Beans & Cotton & Potato & Hemp & Oil & Carbohydrate \\
\hline Yield & 512.50 & 3741.77 & 2247.37 & 102.00 & 2.71 & 64.50 & 1.94 & 645.45 & 11.93 \\
Straw & 512.50 & 5238.48 & 4494.74 & 153.00 & 8.13 & 32.25 & 1.94 & 1290.90 & 1.19 \\
Percentage & 4.37 & 44.65 & 38.31 & 1.30 & 0.07 & 0.27 & 0.02 & 11.00 & 0.01 \\
\hline
\end{tabular}

\section{CONCLUSION}

In the last decades, agricultural non-point source pollution is attracting more and more attention in Henan Province, China, due to the rapid development of agriculture there. This study analyses the agricultural non-point source pollution from 2008 to 2019. The total phosphorus loads showed an increasing trend; The chemical oxygen demand, total nitrogen, and total phosphorus pollution loads showed a decreasing trend. The pesticide use load of Zhoukou, Nanyang, Shangqiu, Xinyang, Xinxiang, and Zhumadian cities were higher in Henan; the plastic film use intensity of Nanyang, Zhoukou, Anyang, Xinyang, Zhumadian, Kaifeng, and Shangqiu was higher; the crop waste discharge amount of Zhumadian, Zhoukou, Nanyang and Shangqiu cities were higher. Due to the development of national policies and agricultural technology, in addition to total phosphorus pollution, the farmland non-point source pollution load is decreasing in Henan Province year by year.

\section{ACKNOWLEDGMENTS}

This research was financed by Henan Province Science and Technology Attack Plan Project (Grant No. 212102310069, 212102300964) and the Third Agricultural Census in Henan Province (Grant No.SNP031).

\section{REFERENCES}

Gu, B.J., Ju, X.T., Chang, J., Ge, Y. and Vitousek, P.M. 2015. Integrated reactive nitrogen budgets and future trends in China. Proc. Natl. Acad. Sci. U.S.A., 112: 8792-8797.

Kuang, L.H., Hou, Y.Z., Huang, F.Q., Guo, Aidi, W.J., Sun, H.J., Shen, L.G., Lin, H.J. and Hong H.C. 2020. Pesticides in human milk collected from Jinhua, China: Levels, influencing factors and health risk assessment. Ecotoxicol. Environ. Saf., 205:111331.

Li, C., Sun, M.X., Xu, X.B. and Zhang, L.X. 2021. Characteristics and influencing factors of mulch film used for pollution control in China: Microcosmic evidence from smallholder farmers. Resour. Conserv. Recycl., 164: 105222.
Li, X., Chen, M., Le, H.P., Wang, F., Guo, Z., Iinuma, Y., Chen, J. and Herrmann, H. 2016. The atmospheric outflow of PM2.5 saccharides from megacity Shanghai to the East China Sea: Impact of biological and biomass burning sources. Atmos. Environ., 143: 1-14.

Li, Y.Q., Zhao, C.X., Yan, C.R., Mao, L.L., Liu, Q., and He, W.Q. 2020.Effects of agricultural plastic film residues on transportation and distribution of water and nitrate in the soil. Chemosphere, 242:125131.

Liu, E., He, W. and Yan C. 2014. 'White revolution' to 'white pollution'-Agricultural plastic film mulch in China. Environ. Res. Lett., 9(9): 091001.

Liu, Y.L., Li, Y. and Zhang, Y.R. 2017. Effect of long-term application of NPK fertilizer on maize yield and yellow soil nutrients sustainability in Guizhou, China. J. Appl. Ecol., 28 (11): 3581.

Qiu, X.H., Duan, L., Chai F.H., Wang S.X., Yu Q. and Wang S.L. 2016. Deriving high-resolution emission inventory of open biomass burning in China based on satellite observations. Environ. Sci. Technol., 50:11779-11786.

Rojas, C., Cea, M., Iriarte, A., Valdés, G., Navia, R. and Cádenas, R J.P. 2019. Thermal insulation materials based on agricultural residual wheat straw and corn husk biomass, for application in sustainable buildings. Sustain. Mater. Techno., 20: 00102.

Sahin, C. and Karpuzcu M. E. 2020. Mitigation of organophosphate pesticide pollution in agricultural watersheds. Sci. Total Environ., 710: 136261.

Sun, M.X., Xu, X.B., Wang, C.D., Bai, Y.L., Fu, C., Zhang, L.X., Fu, R. and Wang Y.T. 2020. Environmental burdens of the comprehensive utilization of straw: wheat straw utilization from a life-cycle perspective, J. Clean. Prod., 259: 120720.

Wang, W.S., Yang, S.Q., Zhang, A.P. and Yang Z.L. 2021. Synthesis of a slow-release fertilizer composite derived from waste straw that improves water retention and agricultural yield. Sci. Total Environ., 768: 144978.

Xue, L.H., Hou, P.F., Zhang, Z.Y., Shen, M.X., Liu, F.X. and Yang L.Z. 2020. Application of systematic strategy for agricultural non-point source pollution control in Yangtze River basin, China. Agric. Ecosyst. Environ., 304: 107148.

Yan, B.J., Yan, J.J., Li, Y.X., Qin, Y.F. and Yang L.J. 2021. Spatial distribution of biogas potential, utilization ratio, and development potential of biogas from agricultural waste in China. J. Clean. Prod., 292: 126077.

Yang, Z.P., Li, X.Y., Wang, Y., Chang, J.Z. and Liu X.R. 2021. Trace element contamination in urban topsoil in China during 2000-2009 and 20102019: Pollution assessment and spatiotemporal analysis. Sci. Total Environ., 758: 143647

Yuan, J.J., Lu, Y.L., Ferrier, R.C., Liu, Z.Y., Su, H.Q., Meng, J., Song, S. and Jenkins A. 2018. Urbanization, rural development, and environmental health in China. Environ. Dev., 28: 101-110.

Zhang, H.Y., Hobbie, E.A., Feng, P.Y., Zhou, Z.X., Niu, L.A., Duan, W.K., Hao, J.M. and Hu, K.L. 2021. Responses of soil organic carbon and crop yield to 33-year mineral fertilizer and straw additions under different tillage systems. Soil Till. Res., 209: 104943. 
Zhang, J.J. and Shou, Y.J. 2021. Research on the construction of agricultural meteorological disaster prevention service system in Henan Province under the rural revitalization strategy. Agric. Biotechnol., 10(1): 79-82.

Zhang, J.K., Cheng, M.T., Ji, D.S., Liu, Z.R., Hu, B., Sun, Y. and Wang, Y.S. 2016. Characterization of submicron particles during biomass burning and coal combustion periods in Beijing, Sci. Total Environ., 562: 812-821.

Zhang, Y.N., Long, H.L., Li, Y.R., Tu, S.S. and Jiang, T.H. 2020. Non-point source pollution in response to rural transformation development: A comprehensive analysis of China's traditional farming area, J. Rural Stud., 83: 165-176.

Zheng, W.L., Luo, B.L. and Hu, X.Y. 2020. The determinants of farmers' fertilizers and pesticide use behavior in China: An explanation based on label effect. J. Clean. Prod., 272(1): 123054.

Zhou, W. and Wang R.M. 2021. Impact of farm size on the intensity of pesticide use: Evidence from China. Sci. Total Environ., 753: 141696.

Zou, L.L., Liu, Y.S., Wang, Y.S. and Hu X.D. 2020. Assessment and analysis of agricultural non-point source pollution loads in China: 1978-2017. J. Environ. Manage., 263: 110400. 